\title{
Designing Interactive Narratives for the Fashion System. MOOC and blended learning in a transdisciplinary design module
}

\section{Ilaria Mariani, Angelica Vandi}

Department of Design, Politecnico di Milano, Italy.

\begin{abstract}
From distributed interactive narratives to games and playful systems, complex interactive projects challenge the fashion ecosystem introducing new possibilities that require innovative and transdisciplinary competencies to be adequately tackled. However, to properly deal with digital media, designers need to master their logic, potentialities, and implications. Therefore the urgency to include such knowledge in building, reframing, and implementing the curricula and design education of today's and tomorrow's fashion designers. This considers the complexity of getting acquainted and implementing vocabulary, design methodologies and practices from other fields of studies. This paper presents the lessons learnt from the first application of the MOOC "Data Science, Visualization and Interactive Narratives for CCIs" to an intensive design module in the Design for the Fashion System. Attention is posed on how it was included in a Blended Learning context to meet the scope and answer previously identified criticalities as providing knowledge from neighbouring fields, and to what extent it succeeded.
\end{abstract}

Keywords: MOOC; blended learning; interactive narratives; transdisciplinary; fashion system; design education. 


\section{Digital Media for the Fashion System: A Multidisciplinary Approach}

The Fashion system is undergoing a major digital transformation, touching all its facets, layers, and processes. This situation progressively brings to a paradigmatic shift where the material and immaterial production of the fashion system is molded by and for the media (Rocamora, 2017), with digital media, mediatization, and its instances impacting and reshaping the field of fashion (Hepp, Hjarvard, \& Lundby, 2015). In this scenario, companies and brands are trying to reach higher maturity levels about digital transformation and its implications for fashion communication. However, the gap between awareness and complete process integration is vast and asks for new professional figures able to exploit contemporary possibilities at best, guiding fashion into an aware implementation of possibilities and resources coming from contemporary media and emerging technologies. This means, for instance, being trained to catch opportunities coming from digital media, dealing with the creation of new narratives able to engage audiences. Therefore the urgency to include such reasonings in building, reframing, and implementing the curricula and design education of today's and tomorrow's fashion designers (Bertola \& Vandi, 2020). To master logics, potentialities and implications of digital media, building on their affordances (Mariani \& Ackermann, 2021; Harrell \& Zhu, 2009), it is necessary to open to a variety of neighboring domains of knowledge (e.g., media studies and game studies) and fields of practice (e.g., storytelling and game design) while reaching out to scholarship in terms of branding, communication, and interaction design. In 2019, the "Advanced Interactive Narrative" (AIN) module was built to address this specific urgency.

Since the last decade, growing attention has been drawn to narratives designed to be distributed across media and games with communication purposes. The ground was particularly fertile due to the coexistence of the need to communicate brands and their values, and the new consumption behaviours that see active user engagement and participation as critical aspects (Mariani \& Ciancia, 2019a). This condition further accelerated because of the covid-19 outbreak, which encouraged fashion companies to increase their efforts for transferring most of their business online while igniting a series of innovative experimentations. An example is Afterworld: The Age of Tomorrow, the game launched by Balenciaga for the Fall 2021 RTW Collection (videogame.balenciaga.com). Fashion design is thereby hybridizing its boundaries (Delgado-Ballester \& Fernández-Sabiote, 2016; Fog, 2010) building imaginative universes of sense that can be actively explored by audiences. The result are multiple attempts of transmedia experiences, by nature articulated on multiple channels, platforms, and media, often shaped as interactive narratives and games, as instances that can be encountered at different times and with different shapes (Dena, 2009; Giovagnoli, 2011).

The first edition of the AIN module in AY 2019/2020 consisted of 8 lessons of 4 hours, all in presence. Although high-quality outcomes were achieved, students showed criticalities 
regarding (i) getting acquainted with vocabulary, design methodologies and practices from other fields of studies, and (ii) understanding the logics and mechanics of complex interactive artefacts as interactive narratives and games. This resulted in a general difficulty in taking in such a high amount of information in a short time and being able to directly apply them for finding creative and innovative design solutions. To prepare the next generations to leverage on the vast and promising opportunities of digital media, coping with the emerging challenges (Kalbaska et al, 2019), the Higher Educational Institutions (HEIs) opened research lines and introduced approaches for providing students with transdisciplinary knowledge (Iannilli \& Sancassani, 2020). Open Educational Resources, e-Learning, and Massive Open Online Courses (MOOCs) are being progressively integrated into HEIs, exploring innovative forms of pedagogies (Griffiths et al., 2015; Morris, 2014). Taking that into account, the second edition of the AIN module (AY 2020/2021) integrated a series of open-access lessons from the MOOC "Data Science, Visualization and Interactive Narratives for CCIs" (pok.polimi.it). Designed for introducing fashion designers to the realm of branding and narrative strategies, part of the MOOC explores storyworld building and interactive narratives for communicating brand values through digital media. Developed within the EU project DigiMood (digimood4cci.eu) (Bertola, Mortati, \& Vandi, 2020), the MOOC allowed reframing the module as a Blended Learning (BL), where the part online (MOOC) anticipates the part in presence (design studio setting).

In the following we present the lessons learnt from applying the MOOC to the AIN module as a BL in AY 2020/2021. Specific attention is posed on how the MOOC met previously identified criticalities and to what extent it succeeded in providing propaedeutic transdisciplinary knowledge for accessing the in-presence design phase.

\section{Design and Research Methodology}

This paper reports on the results obtained applying such an innovative didactic model in a BL context, considering three aspects: (1) instructional and pedagogical achievement, derived from steering informed critical discussions and applying knowledge throughout the design phases; (2) students' group projects as final outcomes; (3) students' perceived quality of the MOOC and BL. While data on (1) and (2) were gathered by means of participant observation with the help of field notes, (3) are derived from the self-assessment that students filled at the end of the module. Through open questions it investigated: (i) perceived benefits from having content delivered via MOOC before the module; (ii) criticalities encountered; (iii) suggestions and (iv) potential issues on how BL could improve/hinder design teaching and learning. The field test involved 65 MSc students from the Final Synthesis Design Studio (MSc in Design for the Fashion System, School of Design, Politecnico di Milano). Equivalent to $2 \mathrm{ECTs}$, it consists of video lectures, readings, quizzes and exercises for verifying learning, and a forum for discussions. Being propaedeutic to the design-studio-setting part of the AIN 
module, the MOOC was to be completed before the starting of the in-presence activities. Analogously its final quizzes were to be passed by the end of the module, since they contributed to the final evaluation. $75 \%$ of the final mark relates to the project developed in teams, while the individual score from the MOOC constitutes the remaining $25 \%$.

\section{From theory to practice: applying transdisciplinary knowledge and tools}

From distributed fashion interactive narratives to games and playful systems, complex interactive projects are challenging the fashion and communication ecosystem introducing new degrees of complexity, which require innovative and transdisciplinary competencies. To tackle this challenge, the AIN module addresses: (i) the role and potentialities of communication systems and user engagement within the fashion domain; (ii) strategies for building communication systems as interactive artifacts able to convey values and meanings; (iii) media affordances, opportunities, criticalities, and risks. To maximise time in class, focusing on designing and reviewing, the MOOC lessons provided beforehand theoretical knowledge, together with tools for storyworld building and interactive narratives. On Sept 3rd 2020, two weeks before the starting of the in-presence module, students were asked to accomplish the MOOC. In parallel, they were required to fill a map for collecting and visualising the skills and attitudes of every participant. On its basis, balanced groups of 6 to 7 persons were built, covering the diverse expertises needed for designing interactive projects. The MOOC introduced a set of narrative tools for the design activity while sharing strategies on how to successfully engage audiences in interactive experiences across media. In particular, the Transmedia Design Framework (Ciancia, 2018), Storyworld Canvas and Character Wheel (Mariani \& Ciancia, 2019b; Piredda et al., 2015) were presented. Scheduled twice a week from Sept 17th to Oct 9th, with 8 blocks of 4 hours, each in-presence lesson started with a theoretical recap and advanced discussions related to the design activities to be run in class, then the tools introduced in the MOOC were applied in contextual exercises. Once in presence, for example, the complex topics of interactive and transmedia storytelling and the techniques for conveying brand values exploiting digital technologies then became the object of case studies analysis. In terms of schedule, Day 1 was devoted to (i) systematise and operationalise knowledge, (ii) understand how to apply it into interactive narrative projects, and (iii) initiate the design phase selecting brand values as starting points for building storyworlds and characters. From Day 2 ahead, the initial short recap on fundamentals, tools, and methods to be applied in that stage of the design was followed by in-presence tutored activities with 30-mins reviews per group to discuss the project and its implementation.

In terms of outcomes, the final results of the AIN module are 9 projects that can be clustered in 5 macro groups: (i) two interactive narratives on Instagram shaped as choose your own adventure stories; (iii) four interactive narratives developed as HTML 5 Choose your-own- 
adventure stories, implemented using the software Twine; (iv) a Role-Playing Game for mobile devices built with RPG Maker; (ii) a transmedia experience with a Twitch campaign, an app with several mini-games, and TikTok for video challenges; (v) a transmedia interactive experience using Instagram and TikTok, an App and dedicated website, and physical events to engage users with a series of challenges.

\section{Conclusion and discussion}

Comparing the two editions of the course, it clearly emerged that the MOOC played a critical role in introducing fashion designers with the domains of branding, communication, and interaction, encouraging novel design trajectories. It provided guidance and equipped students with fundamental knowledge to face such a challenging task. This result is confirmed by the self-assessment that shows (i) the effectiveness of the BL approach and the MOOC in respect to the entire module; and (ii) its didactic quality. The analysis of the selfassessments (Bertola et al., 2020) was compared to the observations conducted during the design activities, also considering the maturity of the final projects. Our application confirmed that integrating the MOOC in a BL context allows to balance flaws discussed in literature (Margaryan, Bianco, \& Littlejohn, 2015) by (i) providing hands-on moments of demonstration of how new knowledge could be applied, (ii) granting timely expert feedback on the learning activities and assignments, (iii) enabling collaborative learning, while (iv) being receptive to the different learning needs surfaced in the class. Nevertheless, concurring with what stated by Holotescu and colleagues (2014), and Morris (2014), even though the MOOC succeeded in reducing content-related gaps, several weaknesses were identified. In the following, benefits and criticalities are discussed.

Getting acquainted with new topics and tools. Leveraging cross-sector innovative practices and transdisciplinary scholarships for creating added value in the Fashion Industry, the MOOC served as an entry point to new topics, so far distant from their domain of study. Even though it introduced students to new topics beforehand, filling eventual gaps of knowledge, the MOOC alone could not fully succeed in making all the students achieve the same level of knowledge. It is the BL situation that triggered learning-by-doing and rebalanced the understanding through specific reviews and discussion.

Contents tackled in little time and applied. From an educational point of view, students grasped knowledge on the state of the art in the game and interactive narrative fields, understanding possibilities for the fashion domain. Although specific lessons introduced students to current trends, media uses, and contemporary experimentations, their limited length implied to reduce complex discourses into short lectures, being often perceived as non adequate in-depth explorations. The key topics were then more extensively recalled in class, becoming the object of tutored design exercises, demonstrating again the relevance of a direct 
exchange to verify the acquisition of knowledge. Throughout the design phases students demonstrated to be able to incorporate most of the methodologies and tools to design complex artefacts introduced, spontaneously and mostly correctly applying them. Also in this case, the exchanges and discussion on the projects that occurred during the reviews made it possible to assess the application and timely fix specific misunderstandings and errors, completing the teaching activity.

More time for design activities and project reviews. Since concepts, terminology, and practices were shared in advance, the in-class time could be effectively spent for informed and critical discussion on more advanced theoretical aspects. This favoured a sort of informal flipped-classroom, where students actively participated in debates. Moreover, it allowed us to spend most of the time on hands-on activities and project reviews.

Students as active learners. As other thematic analyses related to students' perception towards online learning revealed (Galway et al., 2014; Kemp \& Grieve, 2014; Bruff et al., 2013), "convenience" is an important common theme. Having a less stressful approach to lessons contributed to transforming students into active learners. They became responsible for their own learning, schedule their activities, operate on video lessons pausing and rewinding when necessary, personalising the fruition. Moreover, it gave the possibility to spend time searching for insights or investigating topics making use of the references provided. A further support are subtitles, seen as facilitators of learning and understanding.

Benefitting from various experts' knowledge. The learning experience resulted to be enriched because of the presence of many professors and experts involved within the online course, therefore students had more points of view to consider and sources to analyse.

The absence of a learning atmosphere. Even though collaborative learning and feedback among peers are recognized as one of the main quality criteria of MOOCs (Feitosa de Moura, Alexandre de Souza, \& Noronha Viana, 2021), the absence of human interaction, and the lack of engaging and interactive results easily led to increased boredom. Although the POK platform included a discussion forum, it has never been used, demonstrating that it is not a privileged mode of interaction for the target (Bruff et al., 2013).

Online learning for offline discussion. The MOOC was valued as a valuable opportunity to possibly be extended to other topics, contributing to building the curriculum. Further suggestions regarded the possibility (i) to provide extra-materials about design innovation to be later discussed offline, (ii) to further improve the coupling (Bruff et al., 2013) between the online and in-presence activities, showing more concrete case studies from the industries, and (iii) to engage students in more participatory activities and reflections.

Although criticalities are still present and require to be tackled, the field test showed that online learning within a BL context can be successfully integrated to overcome the challenges 
of dealing with complex, transdisciplinary topics in a limited time frame, prompting students to directly apply the acquired knowledge to find creative and innovative design solutions. Especially given current times in which distant learning is a praxis able to open new possibilities to access knowledge, approaching MOOCs as tools for mastering theory in the design discipline is certainly a valuable practice that can no longer be neglected. However, within the design domain, especially the MOOC integration in a BL context emerge as promising, consenting to put into practice the results of the individual learning, having feedback and exchanges on the project being developed. Indeed, when design activities are included, ad hoc reviews are fundamental to impact students' learning. In parallel to the results obtained from the field test, the inclusion of self-assessment activities gave the opportunity to reflect on possible improvements for better integrating MOOCs within traditional, in-presence academic courses.

\section{References}

Bertola, P., Mortati, M., \& Vandi, A. (2020). Future Capabilities for Creativity and Design. Firenze: Mandragora. Retrieved from www.mandragora.it/prodotto/future-capabilitiesfor-creativity-and-design

Bertola, P., \& Vandi, A. (2020). Exploring Innovative Approaches to Fashion Education Through a Multidisciplinary Context for New Professional Profiles. INTED2020-14th International Technology, Education and Development Conference, 4813-4819.

Bruff, D. O., Fisher, D. H., McEwen, K. E., \& Smith, B. E. (2013). Wrapping a MOOC: Student Perceptions of an Experiment in Blended Learning. 9(2), 13.

Ciancia, M. (2018). Transmedia Design Framework: Design-Oriented Approach to Transmedia Practice. FrancoAngeli.

Delgado-Ballester, E., \& Fernández-Sabiote, E. (2016). “Once upon a brand”: Storytelling practices by Spanish brands. Spanish Journal of Marketing-ESIC, 20(2), 115-131.

Dena, C. (2009). Transmedia practice: Theorising the practice of expressing a fictional world across distinct media and environments (PhD Thesis). University of Sydney.

Feitosa de Moura, V., Alexandre de Souza, C., \& Noronha Viana, A. B. (2021). The use of Massive Open Online Courses (MOOCs) in blended learning courses and the functional value perceived by students. Computers \& Education, 161. doi: 10.1016/j.compedu.2020.104077

Fog, K. (2010). Storytelling: Branding in practice. Samfundslitteratur.

Galway, L. P., Corbett, K. K., Takaro, T. K., Tairyan, K., \& Frank, E. (2014). A novel integration of online and flipped classroom instructional models in public health higher education. BMC Medical Education, 14(1), 181. doi: 10.1186/1472-6920-14-181

Giovagnoli, M. (2011). Transmedia storytelling: Imagery, shapes and techniques. Lulu.

Griffiths, R., Mulhern, C., Spies, R., \& Chingos, M. (2015). Adopting MOOCS on campus: A collaborative effort to test MOOCS on campuses of the university system of Maryland. Online Learning, 19(2), 1-15. Retrieved from https://eric.ed.gov/?id=EJ1062937 
Harrell, D. F., \& Zhu, J. (2009). Agency Play: Dimensions of agency for interactive narrative design. AAAI Spring Symposium: Intelligent Narrative Technologies II, 44-52.

Hepp, A., Hjarvard, S., \& Lundby, K. (2015). Mediatization: Theorizing the interplay between media, culture and society. Media, Culture \& Society, 37(2), 314-324. doi: $10.1177 / 0163443715573835$

Holotescu, C., Grosseck, G., Creţu, V., \& Naaji, A. (2014). Integrating MOOCs in Blended Courses. Elearning \& Software For Education, (1).

Iannilli, V., \& Sancassani, S. (2020). Distance learning and pedagogical models: Perspectives and evolutions for the education of designers.

Kalbaska, N., Sádaba, T., \& Cantoni, L. (2019). Editorial: Fashion communication: Between tradition and digital transformation. Studies in Communication Sciences, 18(2). doi: 10.24434/j.scoms.2018.02.005

Kemp, N., \& Grieve, R. (2014). Face-to-face or face-to-screen? Undergraduates' opinions and test performance in classroom vs. Online learning. Frontiers in Psychology, 5, 12781278. doi: 10.3389/fpsyg.2014.01278

Margaryan, A., Bianco, M., \& Littlejohn, A. (2015). Instructional quality of Massive Open Online Courses (MOOCs). Computers \& Education, 80, 77-83. doi: 10.1016/j.compedu.2014.08.005

Mariani, I., \& Ackermann, J. (2021). Post-digital Fairy Tales. Crafting interactive digital narratives to reflect on post-digital challenges. In Transdisziplinäre Begegnungen zwischen postdigitaler Kunst und Kultureller Bildung. Springer.

Mariani, I., \& Ciancia, M. (2019a). Building Interactive Narratives: Characters, Stories and In-Betweens. Experimentations and Critique. EDULEARN19 Proceedings, 6844-6853. doi: 10.21125/edulearn.2019.1643

Mariani, I., \& Ciancia, M. (2019b). Character-driven Narrative Engine. Storytelling System for building interactive narrative experiences. Proceedings of the 2019 DiGRA, 1-19.

Morris, N. P. (2014). How Digital Technologies, Blended Learning and MOOCs Will Impact the Future of Higher Education. Retrieved from https://eric.ed.gov/?id=ED557272

Piredda, F., Ciancia, M., \& Venditti, S. (2015). Social Media Fiction-Designing Stories for Community Engagement. In H. Schoenau-Fog, L. E. Bruni, S. Louchart, \& S. Baceviciute (Eds.), ICIDS (pp. 309-320). Springer.

Rocamora, A. (2017). Mediatization and Digital Media in the Field of Fashion. Fashion Theory, 21(5), 505-522. doi: 10.1080/1362704X.2016.1173349 